\title{
THE COMBINATION OF UPPER LIMB EXERCISE AND RESPIRATORY MUSCLE STRETCH GYMNASTICS ON DYSPNEA AMONG COPD PATIENTS
}

\author{
Ulfa Nur Rohmah ${ }^{1}$, Muhammad Amin ${ }^{2}$, Makhfudli Makhfudli ${ }^{3 *}$ \\ 1,2,3 Airlangga University \\ Email*: ievut_rz@yahoo.com
}

\begin{abstract}
Introduction: Dyspnea becomes important to treat Chronic Obstructive Pulmonary Disease (COPD) patients that had an impact on the limitations of daily activities. The purpose of this study was to determine the effects of Upper Limb Exercise and Respiratory Muscle Stretch Gymnastics combination on dyspnea among COPD patients. Methods: The design of this study was a quasi-experiment. The population was patients who diagnose COPD by spirometry in Surabaya City and Bangil Regency. The total sample was 56 respondents divided into 28 in the intervention group, and 28 in the control group used consecutive sampling. The independent variables were the combination of Upper Limb Exercise and Respiratory Muscle Stretch Gymnastics. The dependent variable was dyspnea. Data were collected using the mMRC Dyspnea Scale. Interventions were given three times a week for a month. Wilcoxon Sign Rank Test to analyzed before and after and Mann Whitney Test to determine between the intervention group and the control group. Results: The result showed that the intervention group was significant differences between dyspnea before and after the intervention with a value of 0.001 ( $p<0.05)$, but the control group was not with a value of $0.160(p>0.05)$. There were differences in dyspnea values between the intervention group and the control group with a value of $0.004(p<0.05)$. Conclusions: the combination of Upper Limb Exercise and Respiratory Muscle Stretch Gymnastics has been shown to reduces dyspnea with COPD patients so that patients can perform as complement pharmacological therapy.
\end{abstract}

Keywords: COPD; dyspnea; respiratory muscle stretch gymnastics; uper limb exercise

\section{INTRODUCTION}

Dyspnea becomes a different physical symptom that usually involves the lungs and heart, so it is important to overcome Chronic Obstructive Pulmonary Disease (COPD) that has an impact on the limitations of daily activities, increases anxiety and depression, and decreases the quality of life (Anzueto \& Miravitlles, 2017). The reduced activity of COPD sufferers due to dyspnea has a prevalence of $39.5 \%-60.2 \%$ in Europe. Moderate to severe dyspnea is interrelated with a more frequent incidence of exacerbations, thus making health status and quality of life worse (Stephenson, Wertz, Gu, Patel, \& Dalal, 2017). Conditions related to COPD continue to increase in the future. It is estimated that in 2060 deaths caused by COPD reached 5.4 million (GOLD, 2020).

Dyspnea is also a strong predictor of mortality in COPD patients and is even a common cause of emergencies; not only does it require expensive long-term treatment that affects the annual economic costs of COPD disease-repairing the dyspnea during lung rehabilitation known to correlate with a decrease in negative emotions that cause dyspnea (Hayen, Herigstad, \& Pattinson, 2013). Improving the quality of life of patients with COPD requires a rehabilitation program that can reduce symptoms, but sometimes it is not a thing to remember to be implemented at the level of tertiary hospital or primary facilities (PDPI, 2016).

Pulmonary rehabilitation is one of the most effective therapies for nonpharmacological measures in COPD patients (Gloeckl, Marinov, \& Pitta, 2013). Upper Limb Exercise as one of the pulmonary rehabilitation programs have benefits in functional capacity training, the performance of daily activities, and quality of life, it can make the diaphragm is well-positioned in the respiratory system and modulates hyperinflation dynamic (Magalhães, Neto, \& Saquetto, 2018). This type of resistance training explained after a meta-analysis obtained satisfactory results in decreasing dyspnea, increasing predicted $\mathrm{FEV}_{1}$ values, 
improving quality of life, skeletal muscle strength, pulmonary physiology, and functional exercise capacity (Liao et al., 2015). Respiratory Muscle Stretch Gymnastics can also reduce dyspnea, improve quality of life, and reduce anxiety due to activation of the limbic system (Toyodera et al., 2013). This exercise shows that intercostal muscle can stretch and activate receptors in the chest wall (Ashwini, Bhagyashri, \& Medha, 2017). Respiratory Muscle Stretch Gymnastics has also been proposed as a possible additional form of rehabilitation that is recommended for patients with COPD (Minoguchi et al., 2002). But the results shown by the two types of combination rehabilitation programs have not yet been thoroughly explained. The purpose of this study was to the effects of the combination of Upper Limb Exercise and Respiratory Muscle Stretch Gymnastics on reducing dyspnea in COPD patients.

\section{METHODS}

This study used a quantitative research design with a quasi-experimental design (prepost test with control group design). This research was conducted from December 2019 to February 2020 in Surabaya City and Bangil Regency, Indonesia. The total sample of this study was 58 respondents who have divided 28 respondents in the intervention group and 28 respondents in the control group. The sampling technique used a consecutive sampling method for two weeks. The inclusion criteria in this study were 1) Diagnosed COPD with Forced Expiratory Volume in One Second/Forced Volume Capacity (FEV $/$ FVC) $\quad<70 \% \quad 2$ ) Characterized by Stable COPD 3) Patients who have not taken systemic steroids for a long time 4) Patients have not cognitive impairment 5) Patients can read and write 6) Willing to be a respondent. The exclusion criteria in this study were 1) Patient has a malignancy 2) Patients have diseases that affect the muscles and joints 3) Patients having exacerbation 4) Patients who are hospitalized three times due to COPD disease in the six months. The dependent variable was the combination of Upper Limb Exercise and Respiratory Muscle Stretch Gymnastics, and the independent variable was dyspnea on COPD patients.

The intervention group received the combination of Upper Limb Exercise and Respiratory Muscle Stretch Gymnastics, while the control group received standard therapy treatment in hospital. The intervention group consisted of 10 minutes of warm-up, 15 minutes of core, and 10 minutes of cooling down. Performance on core session consists of Upper Limb Exercise with total load was $1 \mathrm{~kg}$ for two weeks and $2 \mathrm{~kg}$ for the next two weeks. After 10 minutes for rest, performance continued Respiratory Muscle Stretch Gymnastics with three sessions with 2 minutes each session. Total exercise for 45 minutes, three times a week for a month. The control group received standard therapy treatment in hospital by education and pharmacology.

Data demographic consists of ages, sexes, educations, occupation, Global Initiavive for Chronic Obstructive Lung Disease (GOLD) criteria, and duration of COPD. Pulmonary function tests were measured by spirometry to obtain the percent predicted of $\mathrm{FEV}_{1} / \mathrm{FVC}$ for diagnosing COPD. This study used the modified Medical Research Council (mMRC) Dyspnea Scale to measure dyspnea (Fletcher, Elmes, Fairbairn, \& Wood, 1959). This questionnaire consisted of 0-4 statements with a ratio scale. Descriptive analysis was used for respondent characteristics. The statical test used the Wilcoxon Sign Rank Test with a significant level of $p<0.05$ to analyze the dyspnea value before and after. Then, the Mann-Whitney $\mathrm{U}$ test with a significant level of $\mathrm{p}<0.05$ to analyze post dyspnea value between the intervention group and the control group.

This research protocol was declared to have passed an ethical test by the Health Research Ethics Commission of the Hospital of Universitas Airlangga with a certificate of ethics number 189/KEH/2019 and the Health Research Ethics Commission of the Bangil District Hospital number 
445.1/3255.4.424.202/2019 to protect human

\section{RESULTS}

Table 1 showed that there were 16 people $(57.1 \%)$ were $>65$ years old in the intervention group, and 13 people (46.4\%) were 56-65 years old in the control group. There were 27 people $(96.4 \%)$ were male in the intervention group, and 24 people $(85.7 \%)$ were male in the control group. There were 12 rights and patient welfare from therapy. people $(42.9 \%)$ were senior high school in the intervention group, and 18 people (64.3\%) were elementary school in the control group. There were 16 people $(57.1 \%)$ were no worked in the intervention group, and 14 people $(50 \%)$ were no worked in the control group. There were ten people $(35.7 \%)$ were GOLD 2 criteria in the intervention group, and ten people $(35.7 \%)$ were GOLD 4 criteria in the control

Table 1. Characteristics of respondents $(n=56)$

\begin{tabular}{|c|c|c|c|c|c|c|}
\hline \multirow{3}{*}{ Characteristics } & \multicolumn{4}{|c|}{ Group } & \multirow{3}{*}{ Total } & \multirow{3}{*}{$\%$} \\
\hline & \multicolumn{2}{|c|}{$\begin{array}{c}\text { Intervention }(\mathrm{n}= \\
\mathbf{2 8})\end{array}$} & \multicolumn{2}{|c|}{ Control $(n=28)$} & & \\
\hline & $\mathbf{n}$ & $\%$ & $\mathbf{n}$ & $\%$ & & \\
\hline \multicolumn{7}{|l|}{ Age } \\
\hline 46-55 years & 2 & 7.1 & 4 & 14.3 & 6 & 10.7 \\
\hline $56-65$ years & 10 & 35.7 & 13 & 46.4 & 23 & 41.1 \\
\hline$>65$ years & 16 & 57.1 & 11 & 39.3 & 27 & 48.2 \\
\hline \multicolumn{7}{|l|}{ Gender } \\
\hline Male & 27 & 96.4 & 24 & 85.7 & 51 & 91.1 \\
\hline Female & 1 & 3.6 & 4 & 14.3 & 7 & 8.9 \\
\hline \multicolumn{7}{|l|}{ Education } \\
\hline Elementary school & 5 & 17.9 & 18 & 64.3 & 23 & 41.1 \\
\hline Junior high school & 6 & 21.4 & 5 & 17.9 & 11 & 19.6 \\
\hline Senior high school & 12 & 42.9 & 3 & 10.7 & 15 & 26.8 \\
\hline University & 5 & 17.9 & 2 & 7.1 & 7 & 12.5 \\
\hline \multicolumn{7}{|l|}{ Occupation } \\
\hline No worked & 16 & 57.1 & 14 & 50 & 30 & 53.6 \\
\hline Retired & 5 & 17.9 & 1 & 3.6 & 6 & 10.7 \\
\hline Entrepreneur & 6 & 21.4 & 6 & 21.4 & 12 & 21.4 \\
\hline Farmer & 0 & 0 & 5 & 17.9 & 6 & 10.7 \\
\hline Other & 1 & 3.6 & 2 & 7.1 & 2 & 3.6 \\
\hline \multicolumn{7}{|l|}{ GOLD Criteria } \\
\hline GOLD 1 & 5 & 17.9 & 4 & 14.3 & 9 & 16.1 \\
\hline GOLD 2 & 10 & 35.7 & 5 & 17.9 & 15 & 26.8 \\
\hline GOLD 3 & 8 & 28.6 & 9 & 32.1 & 17 & 30.4 \\
\hline GOLD 4 & 5 & 17.9 & 10 & 35.7 & 15 & 26.8 \\
\hline \multicolumn{7}{|l|}{ Duration of COPD } \\
\hline$\leq 1$ year & 4 & 14.3 & 11 & 39.3 & 15 & 26.8 \\
\hline$<5$ years & 14 & 50 & 10 & 35.7 & 24 & 42.9 \\
\hline $6-10$ years & 6 & 21.4 & 5 & 17.9 & 11 & 19.6 \\
\hline $10-15$ years & 1 & 3.6 & 0 & 0 & 1 & 1.8 \\
\hline$\geq 15$ years & 3 & 10.7 & 2 & 7.1 & 5 & 8.9 \\
\hline
\end{tabular}

*COPD: Chronic Obstructive Pulmonary Disease 
Tabel 2. The combination of Upper Limb Exercise and Respiratory Muscle Stretch Gymnastics on dyspnea in the intervention and control groups

\begin{tabular}{|c|c|c|c|c|c|c|c|c|c|}
\hline \multirow{3}{*}{ Variable } & \multirow{3}{*}{ Grades } & \multicolumn{4}{|c|}{ Intervention group } & \multicolumn{4}{|c|}{ Control group } \\
\hline & & \multicolumn{2}{|c|}{ Pretest } & \multicolumn{2}{|c|}{ Post-test } & \multicolumn{2}{|c|}{ Pretest } & \multicolumn{2}{|c|}{ Post-test } \\
\hline & & $\mathrm{n}$ & $\%$ & $\mathrm{~N}$ & $\%$ & $\mathrm{n}$ & $\%$ & $\mathrm{n}$ & $\%$ \\
\hline \multirow{5}{*}{ Dyspnea } & 0 & 8 & 28.6 & 14 & 50 & 7 & 27.5 & 6 & 21.4 \\
\hline & 1 & 15 & 50 & 12 & 42.9 & 13 & 44.9 & 12 & 42.9 \\
\hline & 2 & 4 & 14.3 & 2 & 7.1 & 7 & 24.1 & 7 & 25 \\
\hline & 3 & 1 & 3.6 & 0 & 0 & 1 & 3.6 & 3 & 10.7 \\
\hline & 4 & 1 & 3.5 & 0 & 0 & 0 & 0 & 0 & 0 \\
\hline \multicolumn{2}{|c|}{ Total } & 28 & 100 & 28 & 100 & 28 & 100 & 28 & 100 \\
\hline
\end{tabular}

Tabel 3. The combination of Upper Limb Exercise and Respiratory Muscle Stretch Gymnastics for dyspnea in COPD patients $(\mathrm{n}=56)$

\begin{tabular}{|c|c|c|c|c|c|c|c|c|}
\hline Variable & Group & $\begin{array}{c}\text { Pre Test } \\
\text { (Mean } \\
\pm \text { SD) }\end{array}$ & $\begin{array}{l}\text { Min- } \\
\text { Maks }\end{array}$ & $\begin{array}{c}\text { Post Test } \\
\text { (Mean } \\
\pm \text { SD) }\end{array}$ & $\begin{array}{l}\text { Min- } \\
\text { Maks }\end{array}$ & Delta & $\mathbf{p}^{*}$ & $\mathbf{p}^{* *}$ \\
\hline \multirow{2}{*}{ Dyspnea } & $\begin{array}{l}\text { Interventi } \\
\text { on }\end{array}$ & $\begin{array}{c}1.04 \pm \\
0.962\end{array}$ & $0-4$ & $\begin{array}{c}0.57 \pm \\
0.634\end{array}$ & $0-2$ & -0.47 & 0.001 & \multirow[t]{2}{*}{0.004} \\
\hline & Control & $\begin{array}{l}1.07 \pm \\
0.813\end{array}$ & $0-3$ & $\begin{array}{l}1.25 \pm \\
0.928\end{array}$ & $0-3$ & 0.18 & 0.160 & \\
\hline
\end{tabular}

p*: Willcoxon Signed Rank Test; p $^{* *}$ : Mann-Whitney U Test

group. There were 14 people $(50 \%)$ who were $<5$ years duration of COPD in the intervention group, and 11 people $(39.3 \%)$ were $\leq$ one years duration of COPD in the control group.

Table 2 explained dyspnea in intervention group, there was 8 repondents $(27.5 \%)$ in grade 0,15 repondents $(51.7 \%)$ in grade 1, 4 repondents $(13.8 \%)$ in grade 2,1 repondents $(3.5 \%)$ in grade 3 and 4 . After 4 weeks of intervention, there was 5 repondents $(51.7 \%)$ in grade 0,12 repondents $(41.4 \%)$ in grade 1,2 repondents $(6.9 \%)$ in grade 2 , and no respondent in grade 3 and 4. Meanwhile, dyspnea in control group, there was 8 repondents $(27.5 \%)$ in grade 0,13 repondents $(44.9 \%)$ in grade 1,7 repondents $(24.1 \%)$ in grade 2, 1 repondents (3.5\%) in grade 3 and and no respondent in grade 4 . After 4 weeks, there was 7 repondents $(24.1 \%)$ in grade 0,12 repondents $(41.4 \%)$ in grade 1,7 repondents $(24.1 \%)$ in grade 2, 3 repondents $(10.4 \%)$ in grade 3 and no respondent in grade 4 .
Table 3 showed that the intervention group obtained the mean of pre-test $1.04 \pm$ 0.962. Whereas after doing the combination of Upper Limb Exercise and Respiratory Muscle Stretch Gymnastics for four weeks the mean value of post-test dyspnea was $0.57 \pm 0.634$ in the intervention group and the delta value was -0.47 . Wilcoxon test results in the intervention group showed that there were significant differences between dyspnea before and after the combination of Upper Limb Exercise and Respiratory Muscle Stretch Gymnastics with a value of 0.001 ( $\mathrm{p}<0.05)$. The control group obtained the mean of pre-test $1.07 \pm 0.813$. Whereas after doing Upper Limb Exercise, the combination of Upper Limb Exercise and Respiratory Muscle Stretch Gymnastics for four weeks, the mean value of post-test dyspnea was $1.25 \pm 0.928$ in the intervention group and the delta value was 0.18 . Wilcoxon test results in the control group showed that there were no significant differences between dyspnea before and after the combination of 
Upper Limb Exercise and Respiratory Muscle Stretch Gymnastics with a value of 0.160 ( $>0.05$ ). Data post-test dyspnea analysis was performed using the Mann Whitney $\mathrm{U}$ Test with a value $0.004(\mathrm{p}<0.05)$ was obtained, which means that there were differences in dyspnea values between the intervention group and the control group.

\section{DISCUSSIONS}

Giving the combination of Upper Limb Exercise and Respiratory Muscle Stretch Gymnastics to dyspnea in COPD patients affects the treatment group. Based on the values before and after treatment, there was a difference in average, namely a decrease in dyspnea in the treatment group. A decrease in dyspnea is characterized by a decrease in dyspnea scores that evaluates the reduction in complaints of shortness of breath in severe sports, shortness of breath when walking on flat ground or climbing inclines, walking slower on a flat surface than others of the same age due to tightness or having to stop breathing when walking on a flat surface, stop after walking 90 meters, and can't leave the house or change clothes.

It is known that all the complications that exist in COPD patients affect physical function decline. This worsens the patient's condition, so it still assumes a lazy lifestyle to avoid unpleasant dyspnea sensations. Inactivity in the body causes an advanced condition in the form of increased dyspnea and even creates a worsening dyspnea circle (AACVPR, 2011). COPD patients also have respiratory muscle weakness that is quadriceps muscle associated with exercise capacity, which affects the severity of COPD (Singer et al., 2011). The severity of dyspnea increased the limitations of the airway so that it is associated with an increase in symptoms of anxiety and depression (Carette et al., 2019). Management of COPD, in principle, should encourage patients to increase their physical activity so that dyspnea is treated and validated (Hanania \& O' donnell, 2019).
During rest, the diaphragm is predominantly active as an inspiring muscle but while doing upper limb exercises some of the upper muscles are involved and participate in the ventilation process, and this exercise stimulates the diaphragm to work so that it can meet ventilation demands (Cuser et al., 1992; Baidya et al., 2018). The type of upper limb exercise in the form of endurance, strengths, or a combination of both is known to reduce the severe dyspnea of COPD patients compared to mild and moderate COPD (Kruapanich et al., 2019). Giving the combination of Upper Limb Exercise and Respiratory Muscle Stretch Gymnastics is known to be involved in respiratory muscles, which have the effect of increasing endurance in respiratory muscles and muscle strength and increasing thoracic muscle activity and expansion of the ribs so that the diaphragm is well-positioned in the respiratory system and modulates hyperinflation dynamic. Besides this exercise, muscles work on accessory muscles that help in the process of ventilation and the work of the diaphragm in the respiratory system in terms of upper extremity exercises (Martinez et al., 1991; Gigliotti et al., 2005; Pan et al., 2012). In exercises involving breathing closely related to intercostal muscles that play a role in aspects of respiratory mechanisms so that the Upper Limb Exercise combination of Respiratory Muscle Stretch Gymnastics can reduce the state of hyperinflation and oxidative capacity and reduce dyspnea.

These results are in line with Wada et al. supported that Respiratory Muscle Stretch Gymnastics combined with the type of physical exercise can reduce dyspnea and increase the capacity of functional exercise in COPD by reducing the activity of respiratory muscles during exercise and increasing the volume of lung capacity in the strength of abdominal muscles (Wada et al., 2016). This is also supported by Emtner and Wadell that said physical exercise has an impact on decreasing dyspnea in COPD patients (Emtner \& Wadell, 2016). Besides, the results of the study of Baidya et al. said that if upper limb exercise 
had a relationship with dyspnea, this was a result of elevation from the hands, thereby reducing the sensation of dyspnea and thoracoabdominal synchronization, increased oxygen consumption, ventilation per minute and increased elimination of carbon dioxide, respiratory rate and pulse rate (Baidya et al., 2018).

An exercise program conducted by COPD patients can improve the acid-base status, overcome the speed of inspiratory nerves and dyspnea by changing the chemoreceptors in the central and peripheral nerves, and partly changing the activity patterns of receptors in locomotor muscles, decreasing respiratory frequency can also reduce dynamic hyperinflation due to dyspnoea. It cannot be tolerated (O'Donnell, Milne, James, de Torres, \& Neder, 2020). Regular and intensive exercise in COPD patients will affect cardiopulmonary physiology, hormonal balance, and biochemical tissue. In general, regular exercise will cause oxidative capacity and decrease ventilation in submaximal workloads and decrease oxygen consumption in submaximal workloads (Tarigan, Ananda, Pandia, Sinaga, \& Maryaningsih, 2019). The pulmonary rehabilitation approach has a role in reducing the incidence of dyspnea. One of the rehabilitation programs is to improve cardiovascular fitness, which reduces fear and anxiety. Increasing the duration of exercise, exercising inspiratory muscles besides can be useful as a whole-body exercise so that reduced hyperinflation in the lungs (Anzueto \& Miravitlles, 2017).

In the control group showed dyspnea values after four weeks of evaluation, there was an increase in the value of dyspnea. Even though pharmacological therapy is still given to patients, this is because the evaluation of pharmacology cannot be done if only for four weeks. Factors influencing the worsening of symptoms in COPD include high levels of GOLD, influenza virus infection, low temperatures, elderly age, smoking, and female sex (Lee et al., 2019). The determinant of the degree of dyspnea increased is also influenced by the increasing grade of airflow limitation (Müllerová, Lu, Li, \& Tabberer, 2014). It is known that the most dominant control group has GOLD criteria 3 and 4; this has an impact on the signs and symptoms of the disease resulting in an increase in dyspnea in the control group.

\section{CONCLUSIONS}

The combination of Upper Limb Exercise and Respiratory Muscle Stretch Gymnastics used in addition to conventional rehabilitation methods, was found to be effective decrease the dyspnea in COPD patients. This exercise can support pharmacological therapy to reduce dyspnea. Not only that, but this exercise is also a safe, easy to do exercise, and requires no money. Futher research is needed by adding with larger number respondents for interventions may be required.

In this study has limitations include duration of exercise is shorter when compared with other studies. Longer duration of exercise such us 8-12 weeks to get best outcomes for patiens with COPD.

\section{ACKNOWLEDGEMENT}

We would like to say thank you so much to all of the participants that really cooperative to participate and research place for support this research very well.

\section{REFERENCES}

AACVPR. (2011). Guidelines for pulmonary rehabilitation programs (4th ed.). Human Kinetics.

Anzueto, A., \& Miravitlles, M. (2017). Pathophysiology of dyspnea in COPD. Postgraduate Medicine, $O(0)$. https://doi.org/10.1080/00325481.2017.1 301190

Ashwini, D., Bhagyashri, S., \& Medha, D. (2017). Comparison of Intercostal Stretch Technique Versus Diaphragmatic 
Breathing on Dyspnoea , Chest Expansion And Functional Capacity in Stable Copd. International Journal of Scientific and Research Publications, 7(5), 256-260.

Baidya, S., Coppieters, M. W., Solomen, S., \& Aaron, P. (2018). Comparison of Cardio Respiratory Responses and Level of Exertion Following Two Common Tests for Arm Exercise Capacity in Patients with COPD. Indian Journal of Physiotherapy and Occupational Thearpyournal of Physiotherapy and Occupational Thearpy, 12(1), 76-81.

Carette, H., Zysman, M., Morelot-Panzini, C., Perrin, J., Gomez, E., Guillaumot, A., ... Risse, B. (2019). Prevalence and management of chronic breathlessness in COPD in a tertiary care center. $B M C$ Pulmonary Medicine, 19(1), 1-7. https://doi.org/10.1186/s12890-0190851-5

Emtner, M., \& Wadell, K. (2016). Effects of exercise training in patients with chronic obstructive pulmonary disease-a narrative review for FYSS (Swedish Physical Activity Exercise Prescription Book). British Journal of Sports Medicine, 50(6), 368-371.

https://doi.org/10.1136/bjsports-2015095872

Fletcher, C. M., Elmes, P., Fairbairn, A., \& Wood, C. (1959). the Significance of Respiratory Symptoms and the Diagnosis od Chronic Bronchitis in A Wokring Population. British Medical Journal, Aug 29, 257-266.

Gloeckl, R., Marinov, B., \& Pitta, F. (2013). Practical recommendations for exercise training in patients with COPD, 22(128), 178-186.

https://doi.org/10.1183/09059180.000005 13

GOLD. (2020). 2020 Report Global Strategy for the Diagnosis, Management, and Prevention of CHronic Obstructive Pulmonary Disease. Retrieved from www.goldcopd.org
Hanania, N. A., \& O' donnell, D. E. (2019). Activity-related dyspnea in chronic obstructive pulmonary disease: Physical and psychological consequences, unmet needs, and future directions. International Journal of COPD, 14, 1127-1138. https://doi.org/10.2147/COPD.S188141

Hayen, A., Herigstad, M., \& Pattinson, K. T. S. (2013). Maturitas Understanding dyspnea as a complex individual experience $\Sigma$. Maturitas, $\quad 76(1), \quad$ 45-50. https://doi.org/10.1016/j.maturitas.2013.0 6.005

Kruapanich, C., Tantisuwat, A., Thaveeratitham, P., Lertmaharit, S., Ubolnuar, N., \& Mathiyakom, W. (2019). Effects of different modes of upper limb training in individuals with chronic obstructive pulmonary disease: A systematic review and meta-analysis. Annals of Rehabilitation Medicine, 43(5), 592-614. https://doi.org/10.5535/arm.2019.43.5.59 2

Lee, J., Jung, H. M., Kim, S. K., Yoo, K. H., Jung, K. S., Lee, S. H., \& Rhee, C. K. (2019). Factors associated with chronic obstructive pulmonary disease exacerbation, based on big data analysis. Scientific Reports, 9(1), 1-8. https://doi.org/10.1038/s41598-01943167-w

Liao, W. H., Chen, J. W., Chen, X., Lin, L., Yan, H. Y., Zhou, Y. Q., \& Chen, R. (2015). Impact of resistance training in subjects with COPD: A systematic review and meta-analysis. Respiratory Care, 60(8), 1130-1145. https://doi.org/10.4187/respcare.03598

Magalhães, C., Neto, M. G., \& Saquetto, M. B. (2018). Effects of upper limb resistance exercise on aerobic capacity, muscle strength, and quality of life in COPD patients: a randomized controlled trial. Clinical Rehabilitation, 1-9. https://doi.org/10.1177/02692155187873 38 
Minoguchi, H., Shibuya, M., Miyagawa, T., Kokubu, F., Yamada-, M., Tanaka, H., \& Altose, M. D. (2002). Cross-over Comparisonbetween Respiratory Muscle Stretch Gymnastics and Inspiratory Muscle Training. Internal Medicine, 41(10), 1-5.

Müllerová, H., Lu, C., Li, H., \& Tabberer, M. (2014). Prevalence and burden of breathlessness in patients with chronic obstructive pulmonary disease managed in primary care. PLOS ONE, 9(1), 70-80. https://doi.org/10.1371/journal.pone.0085 540

O'Donnell, D. E., Milne, K. M., James, M. D., de Torres, J. P., \& Neder, J. A. (2020). Dyspnea in COPD: New Mechanistic Insights and Management Implications. Advances in Therapy, 37(1), 41-60. https://doi.org/10.1007/s12325-01901128-9

Pan, L., Guo, Y. Z., Yan, J. H., Zhang, W. X., Sun, J., \& Li, B. W. (2012). Does upper extremity exercise improve dyspnea in patients with COPD? A meta-analysis. Respiratory Medicine, 106(11), 15171525.

https://doi.org/10.1016/j.rmed.2012.08.00 2

PDPI. (2016). Diagnosis dan Penatalaksanaan $P P O K$. Universitas Indonesia.

Singer, J., Yelin, E. H., Katz, P. P., Sanchez, G., Iribarren, C., Eisner, M. D., \& Blanc, P. D. (2011). Respiratory and skeletal muscle strength in chronic obstructive pulmonary disease: Impact on exercise capacity and lower extremity function. Journal of Cardiopulmonary Rehabilitation and Prevention, 31(2), 111-119. https://doi.org/10.1097/HCR.0b013e3182 033663

Stephenson, J. J., Wertz, D., Gu, T., Patel, J., \& Dalal, anand a. (2017). Clinical and economic burden of dyspnea and other COPD symptoms in a managed care setting. International Journal of COPD, 12, 1947-1959.

Tarigan, A. P., Ananda, F. R., Pandia, P., Sinaga, B. Y. M., \& Maryaningsih, M. (2019). The Impact of Upper Limb Training with Breathing Maneuver in Lung Function, Functional Capacity, Dyspnea Scale, and Quality of Life in Patient with Stable Chronic Obstructive of Lung Disease, 7(4), 567-572.

Toyodera, M., Msaoka, Y., Akai, L., Hanaoka, K., Ono, S., \& Izumizaki, M. (2013). Effects of Respiratory Muscle Stretch Gymnastics on Children s Emotional Responses. Univ $J$ Med Sci, 25(September), 171-179.

Wada, J. T., Borges-santos, E., Porras, D. C., Paisani, D. M., Cukier, A., Lunardi, A. C., \& Carvalho, C. rF. (2016). Effects of aerobic training combined with respiratory muscle stretching on the functional exercise capacity and thoracoabdominal kinematics in patients with COPD: a randomized and controlled trial. International Journal of COPD, $11, \quad 2691-2700$. 